\title{
Práticas de Cuidado À Saúde Mental Ofertadas Pela Estratégia Saúde da Família: Perspectiva dos Médicos e Enfermeiros.
}

\author{
Frateschi, Mara Soares; Cardoso, Carmen Lúcia \\ Faculdade de Filosofia Ciências e Letras de Ribeirão Preto - Universidade de São Paulo - \\ msfrateschi@hotmail.com
}

Introdução: a atual Política Nacional de Saúde Mental brasileira, pautada nos preceitos da Reforma Psiquiátrica, prevê ações centradas em recursos comunitários e em atendimento extra-hospitalar. Nesse contexto, a Estratégia Saúde da Família tem se destacado como uma importante alternativa para a (re) inserção da pessoa em sofrimento mental na sociedade, uma vez que suas equipes estão inseridas no território, próximo às famílias e comunidades. As políticas de Humanização estão diretamente relacionadas ao processo de desinstitucionalização da assistência psiquiátrica e supõem a troca de saberes entre o serviço e a comunidade, o diálogo entre os profissionais e o desenvolvimento de estratégias de trabalho em equipe. Objetivo: Este trabalho objetiva identificar e compreender as práticas de cuidado em saúde mental ofertadas por duas Unidades de Saúde da Família (USF) a partir da perspectivas dos médicos e enfermeiros. Métodos: o trabalho foi realizado em duas USF. Foram realizadas entrevistas abertas e individuais ao médico e ao enfermeiro de cada unidade, totalizando quatro entrevistas. As entrevistas foram audiogravadas e transcritas na íntegra. o material foi submetido à análise seguindo a abordagem qualitativa em e utilizou-se como ferramenta a Análise de Conteúdo. Resultados: Os resultados foram dispostos em três categorias que remetem a práticas de cuidado em saúde mental identificadas pelos entrevistados. a categoria "Acolhimento e Vínculo" aborda as estratégias de cuidado que se pautam no ouvir, estar junto, dar apoio, que é possibilitado pela proximidade entre serviço e comunidade. Entretanto, estas práticas ainda estão atreladas a uma perspectiva demasiadamente assistencialista e individual, em que as queixas são acolhidas no consultório, caso a caso. a categoria "Abordagem multidisciplinar" abarca as práticas desenvolvidas em conjunto com profissionais de diferentes áreas. Tais ações consistem no desenvolvimento de algumas atividades grupais e no apoio mútuo entre os profissionais diante de casos específicos. Embora seja valorizada a troca de saberes entre os profissionais, ainda são escassas as atividades construídas conjuntamente. a categoria "Medicalização e Encaminhamento" trata de práticas prioritariamente ancoradas no modelo médico-hegemônico, em que o fazer em saúde se centra principalmente no profissional médico. Conclusões: Os entrevistados reconhecem e valorizam as estratégias pautadas na perspectiva biopsicossocial, visando a oferta de um cuidado mais humanizado, longitudinal e integral. Todavia, observa-se que o cuidado à saúde mental pautase ainda numa lógica centrada na consulta médica, no encaminhamento para especialistas e na medicalização. Identificar e compreender como são pensadas e executadas as práticas de cuidado em saúde mental torna-se, portanto, essencial para a consolidação de novas formas de pensar e fazer saúde, comprometidas com a equidade, a cidadania e o respeito às diferenças. (Financiamento: FAPESP)

Frateschi, Mara Soares; Cardoso, Carmen Lúcia. Práticas de Cuidado À Saúde Mental Ofertadas Pela Estratégia Saúde da Família: Perspectiva dos Médicos e Enfermeiros.. In: Anais do Congresso Internacional de Humanidades \& Humanização em Saúde [= Blucher Medical Proceedings, num.2, vol.1]. São Paulo: Editora Blucher, 2014. ISSN 2357-7282

DOI 10.5151/medpro-cihhs-10630 